05

\title{
Формирование многомасштабной структуры при ударном нагружении твердого тела
}

\author{
(С) Ю.И. Мещеряков ${ }^{1}$, Н.И. Жигачева ${ }^{1}$, Г.В. Коновалов ${ }^{1}$, А.К. Диваков ${ }^{1}$, В.А. Морозов ${ }^{2}$ \\ ${ }^{1}$ Институт проблем машиноведения РАН, Санкт-Петербург, Россия \\ ${ }^{2}$ Санкт-Петербургский государственный университет, Санкт-Петербург, Россия \\ E-mail: ym38@mail.ru
}

Поступило в Редакцию 25 ноября 2020г.

В окончательной редакции 25 ноября 2020 г.

Принято к публикации 16 декабря 2020г.

\begin{abstract}
С целью изучения процессов многомасштабного структурообразования вдали от термодинамического равновесия проведена серия экспериментов по ударному нагружению мишеней из алюминиевых сплавов импульсами наносекундной длительности, инициируемыми метательной установкой и импульсным электронным пучком. В обоих случаях в приконтактной области ударного нагружения выявлены крупномасштабные структуры мезоскопического уровня, размеры которых с увеличением толщины мишеней уменьшаются, в то время как материал мишени становится однородным. Переход к однородной структуре в алюминии 1565 происходит при толщине мишени $2.2 \mathrm{~mm}$, одновременно изменяется макроскопический отклик (откольная прочность) материала на ударное нагружение.
\end{abstract}

Ключевые слова: ударное нагружение, многомасштабная структура.

DOI: 10.21883/PJTF.2021.07.50790.18633

Как показывают экспериментальные и теоретические исследования, определяющими факторами структурообразования в твердом теле оказываются не только вещество и его состояние, но и скорость ввода импульса нагрузки и интенсивность энергообмена между масштабными уровнями [1-4]. На макроскопическом уровне смена механизма и масштабного уровня динамического деформирования проявляется в изменении характера отклика материала на ударное нагружение. На микроуровне смена масштабного уровня определяется по структурным изменениям материала. В соответствии с современной теорией транспортных процессов в конденсированных средах в начальные моменты времени динамического нагружения формируются крупномасштабные структуры, отвечающие за процессы волнового переноса энергии, и только после того, как устанавливается равновесие, инициируются диффузионные процессы $[5,6]$. В алюминии и его сплавах, согласно данным по затуханию упругого предвестника, равновесное состояние устанавливается в течение $200-300 \mathrm{~ns}$, что соответствует $1-2 \mathrm{~mm}$ [7].

В настоящей работе в порядке дальнейшего изучения процессов динамического структурообразования проведены эксперименты по импульсному нагружению мишеней из алюминиевых сплавов Д16 и 1565. В качестве контролирующего параметра интенсивности энергообмена между масштабными уровнями динамического деформирования и смены механизма структурообразования принят так называемый „дефект“ массовой скорости, который определяется разностью между скоростью ударника при симметричном соударении $\left(\rho_{i m p} C_{i m p}=\rho_{t} C_{t}\right)$ и максимальным значением скорости свободной поверхности $\left(\delta U_{\text {def }}=U_{\text {imp }}-U_{\max }^{f s}\right)[6]$.

Ударные испытания материалов проводились в двух режимах. В первом режиме осуществлялось нагружение в условиях одноосной деформации плоских мишеней разной толщины, для этого использовалась легкогазовая ударная установка. Скорость ударника из алюминиевого сплава Д16 во всех опытах была примерно одинаковой и равной $405 \pm 5 \mathrm{~m} / \mathrm{s}$. Для регистрации отклика мишени на ударное нагружение использовался скоростной интерферометр [8]. На рис. 1 представлены кривые зависимости откольной прочности $W$, размера структурных элементов $L$ и дефекта скорости $\delta U_{d e f}$ от толщины мишени. Видно, что при толщине мишени $2.2 \mathrm{~mm}$ ход

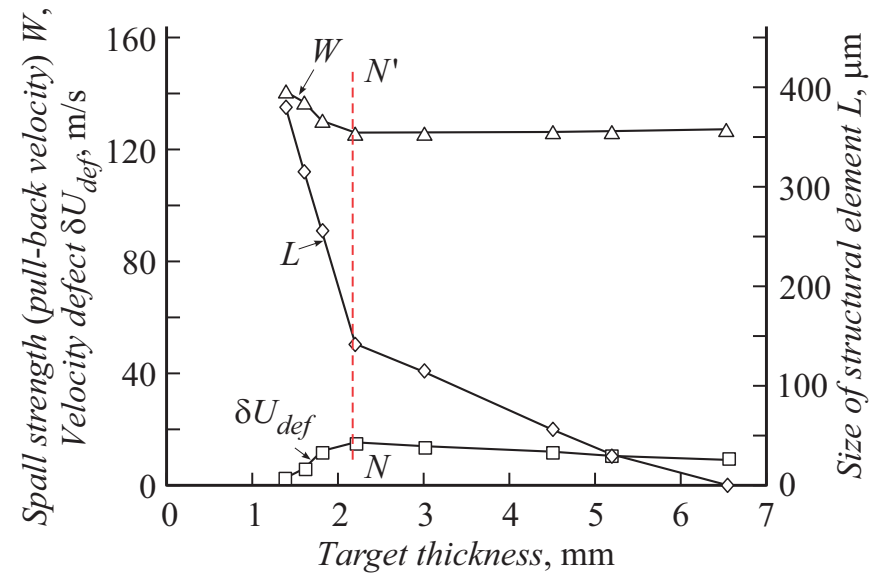

Рис. 1. Зависимости откольной прочности $W$, дефекта скорости $\delta U_{d e f}$ и размера структурного элемента $L$ от толщины мишени для алюминиевого сплава 1565. 

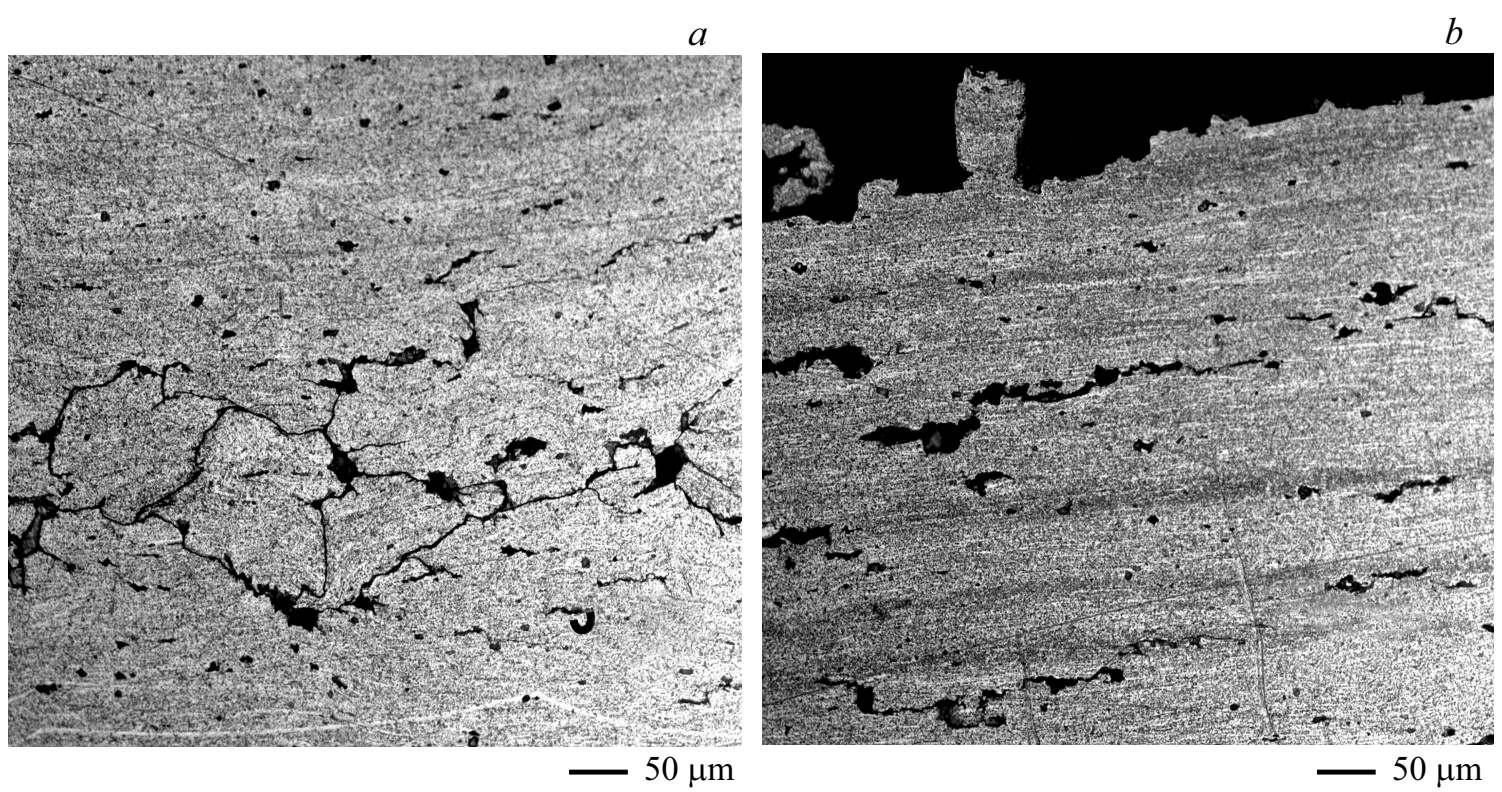

Рис. 2. Структура откольной зоны в алюминиевом сплаве $1565 . a-$ толщина мишени $2.2 \mathrm{~mm}, b-$ толщина мишени $6.56 \mathrm{~mm}$.

указанных характеристик резко меняется (линия $N N^{\prime}$ ). Изменение величины дефекта скорости при изменении толщины мишени свидетельствует о том, что интенсивность энергообмена между структурными уровнями также меняется. Наиболее заметное изменение дефекта скорости происходит в приконтактной области ударного нагружения. В твердом теле изменение интенсивности энергообмена и масштаба структуры сказывается на величине динамической прочности материала: откольная прочность алюминиевого сплава 1565 также изменяется там, где изменяется дефект скорости. В связи с этим можно считать, что дефект скорости является контролирующим параметром ударно-волнового поведения твердотельных материалов.

Смена характера структурообразования подтверждается микроструктурными исследованиями образцов. В алюминиевом сплаве 1565 перелом в отклике материала на ударное нагружение (в поведении откольной прочности и дефекта скорости) происходит при толщине мишени $2.2 \mathrm{~mm}$ (рис. 1). Это изменение коррелирует с изменением масштаба структурных элементов $L$, размер которых сначала пороговым образом изменяется при толщине мишени $2.2 \mathrm{~mm}$, а затем постепенно уменьшается с ростом толщины мишени.

Аналогичная ситуация, как известно, имеет место для турбулентности, на начальном этапе развития которой крупномасштабные вихри участвуют только в переносе энергии, и лишь на больших временны́х интервалах, после перехода от волновых к диффузионным процессам массопереноса, турбулентное состояние нивелируется и в процессе равновесного массопереноса осуществляется обмен энергией со средой [9]. На рис. 2 представлены фотографии микроструктуры откольной зоны мишеней толщиной 2.2 и $6.56 \mathrm{~mm}$. На рис. 2, $a$ видны замкну- тые структурные образования со средним размером $\sim 150 \mu \mathrm{m}$, ограниченные трещинами и порами. При толщине мишени $1.38 \mathrm{~mm}$ средний размер структурного элемента составляет $\sim 380 \mu \mathrm{m}$. В зоне откольного разрушения мишени, где действует всестороннее растягивающее напряжение, сохраняется структура, которая зародилась в приконтактной области ударного нагружения. С увеличением толщины мишени и длительности импульса нагрузки процесс динамического деформирования приходит к равновесию, вследствие чего крупномасштабные структуры исчезают и процесс динамического деформирования переходит к однородной стадии. В этих условиях откольное разрушение материала протекает путем расслоения (рис. 2, $b$ ).

Во второй серии опытов мишени из алюминиевого сплава Д16 нагружали импульсами давления, создаваемыми воздействием сильноточного пучка электронов. Пучок генерировался сильноточным электронным ускорителем „Нева-01“ (НИИ электрофизической аппаратуры им. В.Д. Ефремова (Санкт-Петербург) [10]. Чтобы избежать влияния зоны облучения на параметры ударной волны, электронный пучок предварительно воздействовал на пластину-анод ускорителя, а затем давление передавалось в исследуемый образец. Максимальная величина давления составила $4.0 \mathrm{GPa}$ при длительности импульса $40 \mathrm{~ns}$. Импульсное нагружение привело к зарождению крупномасштабных структур, которые представляют собой объемные образования, границы которых формируются за счет разницы в скоростях их движения. В условиях кратковременного воздействия всестороннего растягивающего напряжения в откольной зоне мишени разрывы в скорости трансформируются в разрывы по смещению. В этом случае реликтовые остатки этих структур визуализируются благодаря появлению 

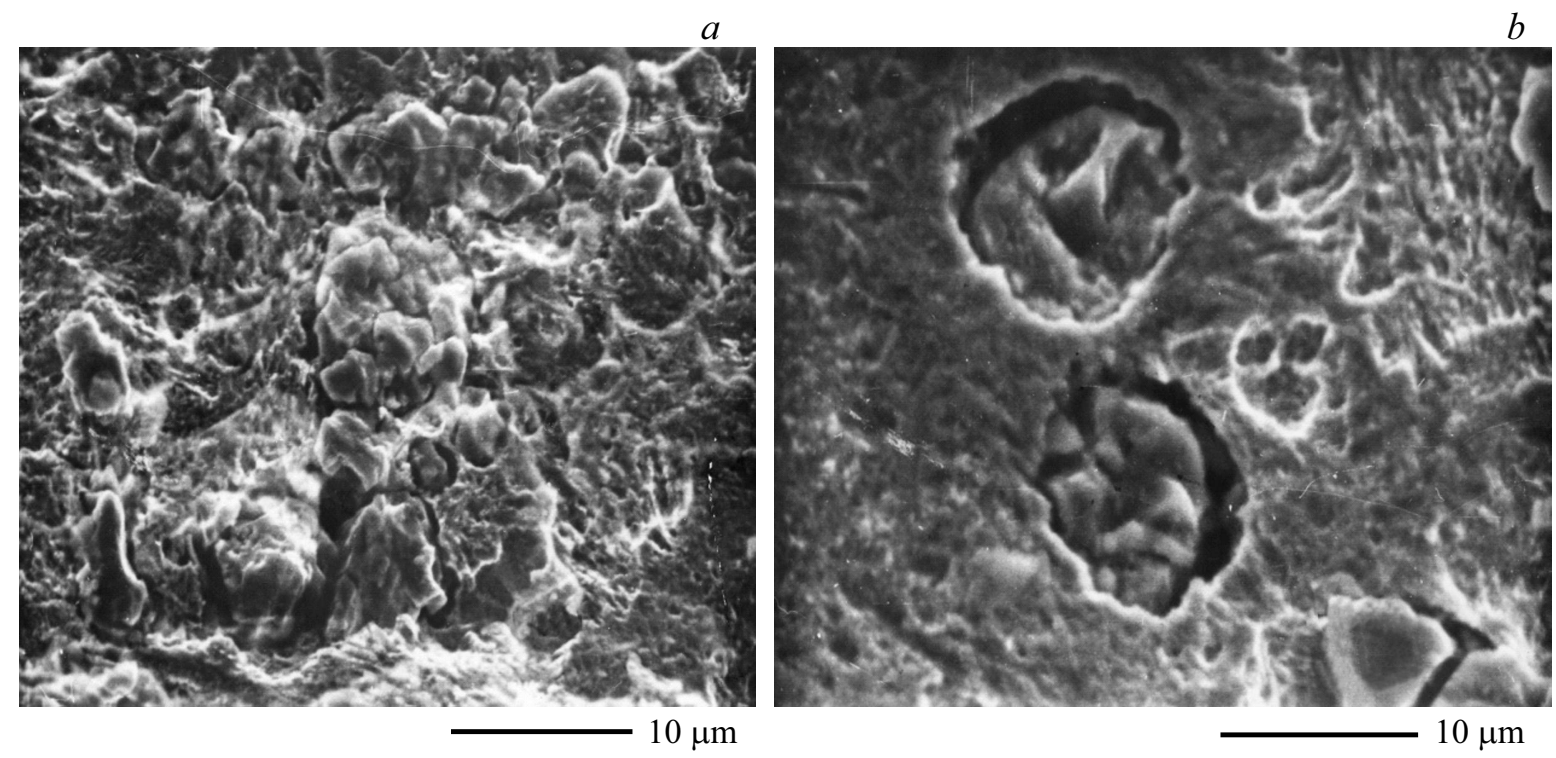

Рис. 3. Крупномасштабные структуры в откольной зоне мишени из сплава Д16 при нагружении импульсным электронным пучком. $a-$ начальная стадия формирования крупномасштабной структуры в приконтактной зоне мишени; $b-$ реликтовые остатки крупномасштабной структуры в откольной зоне мишени.

трещин и пор вокруг указанных структур. Примеры таких структур для начальной и конечной стадий их формирования представлены на рис. 3 .

Проведенные исследования показывают, что в приконтактной области ударного и импульсного нагружения динамическое деформирование и разрушение твердотельных материалов протекают в условиях сильной неравновесности и гетерогенизации структуры, при которой зарождаются крупномасштабные структуры мезоуровня $(1-10 \mu \mathrm{m})$.

\section{Благодарности}

Исследования проводились с использованием высокоскоростных ударных установок Института проблем машиноведения РАН, а также уникальной научной установки - сильноточного электронного ускорителя „Нева-01“ НИИ электрофизической аппаратуры им. В.Д. Ефремова. Авторы благодарят сотрудников НИИЭФА им. В.Д. Ефремова, принимавших участие в обеспечении работы сильноточного электронного ускорителя.

\section{Конфликт интересов}

Авторы заявляют, что у них нет конфликта интересов.
[3] М.А. Соковников, Д.А. Биланов, В.В. Чудинов, С.В. Уваров, О.А. Плехов, А.И. Терехина, О.Б. Наймарк, Письма в ЖТФ, 40 (23), 82 (2014).

[4] В.В. Рыбин, В.Н. Переверзенцев, Ю.В. Свирина, ЖТФ, 87 (5), 726 (2017). DOI: 10.21883/JTF.2017.05.44446.2029

[5] Т.А. Хантулева, Нелокальная теория неравновесных прочессов переноса (Изд-во СПбГУ, СПб., 2013).

[6] Т.А. Хантулева, Ю.И. Мещеряков, Физ. мезомеханика, 18 (1), 14 (2015).

[7] T.E. Arvidsson, Y.M. Gupta, G.E. Duvall, J. Appl. Phys., 46 (10), 447 (1975).

[8] Н.А. Златин, С.М. Мочалов, Г.С. Пугачев, А.М. Брагов, ЖТФ, 43 (9), 1961 (1973).

[9] T. Hintze, Turbulence (Mc Graw Hill, Inc., N.Y., 1962).

[10] В.В. Белогорский, Н.Г. Беручев, Е.П. Большаков, В.В. Еремкин, В.В. Ершов, Ю.А. Истомин, О.П. Печерский, Л.В. Смирнов, А.Г. Сыромятников, Т.С. Чернобровина, В.И. Чернобровин, Исследование работы сильноточного наносекундного ускорителя электронов НЕВА-01. Препринт К-0606 (НИИЭФА им. В.Д. Ефремова, Л., 1983).

\section{Список литературы}

[1] А.Ф. Беликова, С.Н. Буравова, Е.В. Петров, ЖТФ, 83 (8), 68 (2013).

[2] А.С. Власов, А.Б. Синани, ЖТФ, 87 (7), 1033 (2017). DOI: $10.21883 /$ JTF.2017.07.44674.1992 